\title{
Impacts of Selected Fungal Toxins on the Inducement of Agarwood in Gyrinops walla
}

\author{
Subasinghe S.M.C.U.P. ${ }^{1}$, Withanage S.V. ${ }^{1 *}$, Fernando T.H.P.S. ${ }^{2}$ \\ ${ }^{1}$ Center for Forestry \& Environment, University of Sri Jayewardenepura, Sri Lanka \\ ${ }^{2}$ Plant Pathology \& Microbiology Department, Rubber Research Institute, Sri Lanka \\ *sohaniw@gmail.com
}

\begin{abstract}
Agarwood is a resinous wood substance that is produced as a non-specific host response to wounding, insects or microbial invasion by certain trees of family Thymelaeaceae. Most species of Aquilaria and a few species of Gyrinops, Aetoxylon and Gonystylus are capable of producing agarwood. Gyrinops walla is the only agarwood producing tree growing in Sri Lanka which is believed to be endemic. Previous studies have identified that the two fungal species Aspergillus niger and Fusarium soloni are capable of inducing agarwood formation in G. walla. Since those fungi form toxins, it can be assumed that the agarwood production is induced by fungal toxins. Although the ability of fungal species in agarwood production inducement was studied previously, the impact of toxins on agarwood production was never tested. Therefore the present study is aimed to investigate the ability of these mycotoxins to induce the formation of agarwood in G. walla. Secondary metabolites were extracted from one selected isolate of $A$. niger and $F$. soloni. The presence of toxins in those metabolites was confirmed through a structured leaf bioassay. Volumes of $5 \mathrm{ml}$ and $10 \mathrm{ml}$ of extracted toxins were inoculated into live healthy $G$. walla trees and the formation of agarwood resin within the stem was observed using tissue samples collected at $10 \mathrm{~cm}$ above and below the inoculation points, 3 months after inoculation. Agarwood resins were extracted from those tissues and resin constituents were analysed by GC-FID method. According to the results, tissue samples obtained from trees inoculated with toxins of $F$. solani showed higher average resin content $(1.69 \% \pm 0.33)$ than the trees inoculated with toxins of $A$. niger $(0.81 \% \pm 0.26)$ though there was no significant difference $(\mathrm{F}=2.34, \mathrm{p}=0.099)$. The highest resin percentage was observed with $5 \mathrm{ml}$ inoculation of $F$. solani toxins $(2.00 \% \pm 0.82)$. Several resin constituents considered as important markers in identifying agarwood aroma were present in the resins extracted from inoculated trees. Among them, 6-acetyl-7-hydroxy-2,2-dimethyl benzopyran showed the highest abundance. However, the presence of common resin constituents was higher in the inoculation of toxins of $A$. niger when compared to toxins of $F$. solani. This study identified that fungal toxins can be used as an effective inoculant to trigger the formation of agarwood in $G$. walla. However, further research is recommended to verify above observations.
\end{abstract}

Keywords: Agarwood, Gyrinops walla, Fungal toxins, Aspergillus niger, Fusarium solani

Proceedings of the $22^{\text {nd }}$ International Forestry and Environment Symposium 2017 of the Department of Forestry and Environmental Science, University of Sri Jayewardenepura, Sri Lanka 